\title{
A Methodology to Assess the Benefits of Smart Order Routing
}

\author{
Bartholomäus Ende, Peter Gomber, Marco Lutat, and Moritz C. Weber \\ Goethe-University Frankfurt, E-Finance Lab, Grüneburgplatz 1, 60323 Frankfurt, Germany
}

\begin{abstract}
Smart Order Routing technology promises to improve the efficiency of the securities trading value chain by selecting most favourable execution prices among fragmented markets. To measure the extent of sub-optimal order executions in Europe we develop a simulation framework which includes explicit costs associated with switching to a different market. By analysing historical order book data for EURO STOXX 50 securities across ten European lectronic markets we highlight an economically relevant potential of Smart Order Routing to improve the trading process on a gross basis. After the inclusion of switching costs (net basis), the realisability of this value potential depends on whether the user can directly access post-trading infrastructure of foreign markets or has to make use of intermediaries' services.
\end{abstract}

Keywords: Electronic Markets, Process Optimisation, Smart Order Router.

\section{Introduction}

In securities trading, different trading intentions are aggregated at exchanges to discover prices. Until the late 1980s, this process has been conducted by direct human interaction at exchange floors. Then, new trading concepts originated from an ITdriven transformation of trading [1]. Following [2] we measure the potential to generate value of one such IT concept called Smart Order Router (SOR).

The focus of our analysis is the entire securities trading value chain: starting from the investment decision it includes all required stages up to the legal transfer of ownership of traded securities (cf. upper horizontal flow path in Figure 1): trading is a traditionally intermediated business [3]. Thus, investors (step 1) communicate their trade interests to human brokers (step 2) who search for counterparties at exchanges to complete trades (step 3). Trade confirmations are communicated to post-trading infrastructure providers: in the clearing stage (step 4) settlement obligations are determined for each market participant towards all counterparties. That way clearing provides a risk management function and for efficiency reasons a pooling of multiple trades among counterparties to determine the surplus obligations (netting). Settlement (step 5) is “...the act of crediting and debiting the transferee's and transferor's accounts respectively, with the aim of completing a transaction in securities" [4, p. 5]. It takes place at a Central Securities Depository (CSD). Custody (step 6) of shares as well as ownership information is provided by a CSD. For domestic settlement each country typically possesses its own CSD whereas International CSDs (ICSDs) enable access to foreign CSDs for international transactions. 


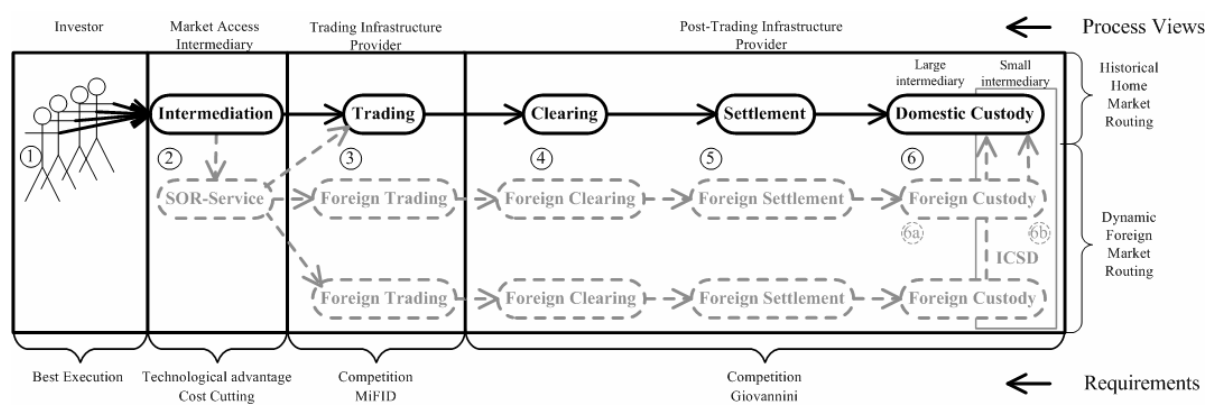

Fig. 1. Traditional securities value chain and changes induced by a SOR

In the US, alternative trading systems have been introduced at the end of the last century, leading to a fragmentation of markets [1]. To enforce best (order) execution, current US regulation (RegNMS) requires mandatory routing of orders from the market initially receiving the order to the one offering the best price. In Europe, no such obligations are in place. Before the Markets in Financial Instruments Directive (MiFID) was introduced in November 2007, stock trading had to take place at national stock exchanges (concentration rule) in various European states. Thus, nearly all trading activity in a security was conducted in its home market [1]. To foster competition and to take advantage of technological developments, MiFID abolished these concentration rules. Besides traditional exchanges, this enables the emerge of so-called multilateral trading facilities (MTFs) like Chi-X, BATS or Turquoise. Relevant market share gains of MTFs [5] in European securities document increasing market fragmentation. To strengthen customer requirements for best execution, MiFID obliges intermediaries to execute customer orders on terms most favourable to the client, i.e. the investor. Within the post-trading stages the European commission aims at fostering competition as it has identified multiple cross-system barriers for cost efficiency [6].

To implement best execution by intermediaries, two alternatives prevail: either to rely on pre-defined static order routing rules, mostly targeting only one market per security (e.g.: the national stock exchange or the respective security's home market) or to employ a dynamic routing by an IT concept called SOR. The technological foundation of a SOR is the ability for remote access to multiple markets' electronic order books where available trade intentions are displayed (cf. right hand side of Figure 2). Connectivity is provided by standardised components such as FIX and third party infrastructure like the SWIFT secure IP network. Based on (1) real-time market data, (2) current trading costs information as well as (3) rules representing client preferences, a SOR performs an automated search for trading opportunities across multiple markets. Herein it aims at splitting an order and routing suborders to the most appropriate market combinations: for an incoming parent order (buy 1,000 shares in Figure 2) the SOR determines how it is sliced and how the individual child orders (buy 600 shares at exchange B and 400 at the MTF) are routed to appropriate marketplaces.

[7] reveal best execution implementations to rely mostly on predefined, static routing rules and only a very low usage of real-time SOR solutions up to now. One reason might be the access to post-trading infrastructures: large institutions apply directaccess 


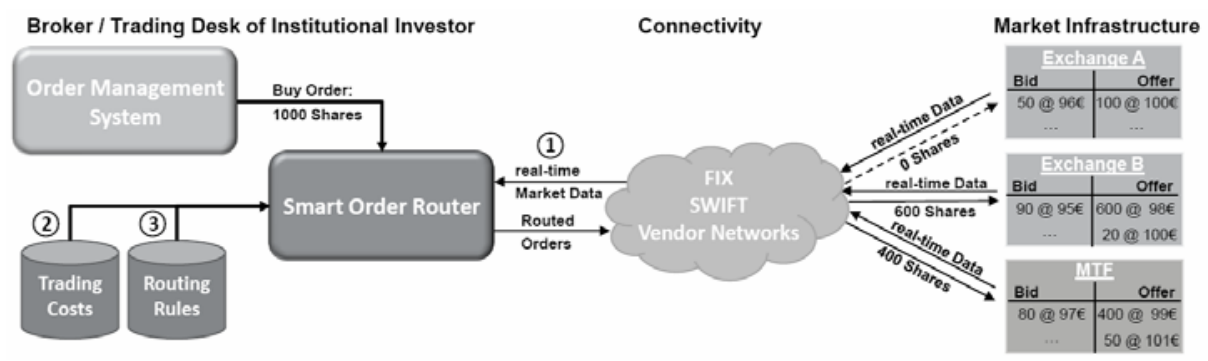

Fig. 2. Operating principle of a SOR Service

(cf. step 6a in Figure 1) whereas smaller ones require intermediaries to the foreign infrastructure by e.g. ICSDs (cf. step $6 \mathrm{~b}$ in Figure 1) incurring high transfer costs. Therefore, the general question for the business value of SOR arises [8] and the two related research questions for this paper are:

(1) Is a static routing process efficient in fragmented European equity markets?

(2) Does SOR technology enable for relevant efficiency improvements within the trading process?

To answer these questions, we develop a general simulation framework for identifying sub-optimal order executions. It can be applied to public data and accounts for explicit costs associated with switching a trade from the original to a different market in European cross-system trading. To infer cost boundaries, two model users are assumed: one user for an intermediated high-cost scenario and another acting in a lowcost scenario with direct access to the respective post-trade infrastructures. Our framework is then validated on a sample of EURO STOXX 50 constituents.

Applied on a continuous basis our framework provides threefold insights: firstly, intermediaries (brokers and trading desks of institutional investors) can assess the value generation potential of SOR systems on a net basis, i.e. including transaction costs. Secondly, investors can judge the relevance of SOR services for their intermediary choice. Thirdly, regulators can evaluate the effectiveness of the MiFID best execution provisions relative to the RegNMS regime. By comparing the gross (i.e. excluding transaction costs) with the net results the impact of transaction costs, specifically those for clearing and settlement, on the order routing decision is shown.

The remainder of this paper is structured as follows: section 2 reviews related literature, section 3 elaborates on the employed methodology and presents assumptions for the applied transaction cost scenarios. In section 4 the data set is described, followed by our results in section 5 . Section 6 concludes.

\section{Related Literature}

Beside the particular perspective of electronic securities trading, this paper is motivated by multiple cross-domain relations in information systems research: 
We evaluate the business value of an IT concept with a focus on potential vs. realised value as defined by [9]. These value categories are used to analyse process-driven and market-driven value flows as well as unrealised value flows caused by barriers and limits affecting these processes. [10] differentiate between ex ante project selection and ex post investment evaluation in analysing IT values. The potential value is construed as "business payoff expected from an ideal technology solution" (p. 133) like the cost savings of an assumed optimal SOR. As this perspective implies a corporate point of view [11] argue to "move away from firm-level output measures, particularly financial measures, of business value in favour of process-oriented measures" (p. 77). This motivates the process-orientated perspective within our study. Further this choice is substantiated by the limitation incurred by directly measuring at firm-level (but not at process-level) how and where business value is created by IT.

[12] highlight the ability of simulations to serve as a basis for business process optimisation. Their results are backed by [13], who illustrate the impact of integrated process optimisation for multi-criteria stakeholder process views. Both lead to the simulation of business process that is influenced by the criteria of multiple stakeholders (cf. Figure 1). Amongst others, direct measurements and computer simulations are described. Energy cost simulations of globally distributed computer centres by [14] prove possible economic gains of smart routing even outside financial markets. Their results outline potential savings of $40 \%$ for data centres which dynamically route their work load to regions with low energy costs. For reliable smart routing simulations, [14]'s analysis shows also the demand for a market scope instead of a firm perspective. At firm-level it is not possible to measure process efficiency for the entire market. On top, firms try to conceal their process strategies to retain their comparative advantages. All three findings strengthen our decision for a market-oriented analysis setup.

Regarding finance literature on SOR technology in particular, [15] argue suboptimal trade executions on security markets to be induced by a lack of automated routing decisions. Empirical studies by $[16,17]$ investigate the impact of automated order flow on markets. They underline the high percentage of orders originating from Algorithmic Trading. Further, [18] show the business value of algorithms by comparing their overall trading costs with those of human brokers. On top, [19] highlight the importance of overall transaction costs. The latter two investigations' results stress the need to employ an approach including costs.

This paper's contribution to the existing literature is twofold: firstly, it introduces a potential vs. realised value framework for order routing in fragmented markets. Secondly, to the knowledge of the authors it is the first paper which empirically analyses the trading process efficiency after the introduction of MiFID. That way it includes switching costs (i.e. transactions costs) which are relevant for the European case.

\section{Methodology and Research Framework}

For the empirical analysis of the order execution process, we develop a general simulation framework to calculate the savings per trade (cf. Figure 3). As data including individual market participants' identities and cost structures is only available within 


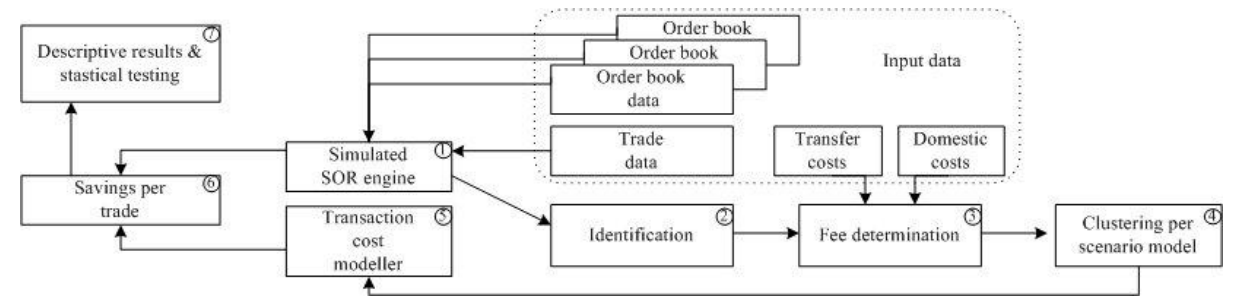

Fig. 3. Research framework simulating SOR and modelling transaction costs

banks, our framework is specifically designed to employ public market data and fees. It is composed of two main artefacts: a dynamic SOR engine and a static transaction cost modeller. These are described in more detail below:

The SOR engine iterates stepwise through historical trade data, consisting of security names, time stamps, trade price and volume. This data is compared to the historical order book situations of all markets where the trade could have been executed alternatively. According to the information whether a trade could be completed at an alternative market for a better price or not it is classified as executed sub-optimally or optimally respectively (cf. Figure 3, step 1 and Appendix ${ }^{1}$ A I for an example).

One might face a situation where some alternative markets offer a better limit price, but with a number of shares insufficient to fully execute the original trade. This kind of sub-optimal execution is sub-classified as "partial". Those sub-optimal executions where the full number of shares might be executed at a better price are labeled as "full". A sub-optimal execution (partial or full) is found if at least one marketplace exists where a strictly positive amount of savings could be realised without considering switching costs. We select the market with the highest potential overall savings for the trade and define the realisable cost difference as "gross savings".

This process improvement information (gross sub-optimal executions) is directed to the transaction cost modeller. This component determines the additional cost to complete the trade at the alternative market. Therefore, cost specific parameters like trade value, security and market characteristics are analysed, as some markets, feature special fees for foreign stocks (cf. Figure 3 step 2). These fees are taken from a database which consists of costs for trading, clearing and settlement in each respective market (domestic costs) and transfer costs among different CSDs (cf. Figure 3 step 3). For reliable results we calculate multiple scenario configurations (cf. Figure 3 step 4). As noticed in [6] it is not trivial to estimate post-trading process costs for European cross-system trades. This is discussed more detailed in the next sub-section which also elaborates on our specific simulation parameters. With the results from clustering by scenarios, specific transaction costs can be determined (cf. Figure 3 step 5). These switching costs are compared to the gross savings generated by using the SOR engine. In the following savings reduced by transaction costs are referred to as "net savings" per trade (cf. Figure 3 step 6) which are aggregated in the last step 7.

\footnotetext{
${ }^{1}$ The Appendix is available at http://www.efinance.wiwi.uni-frankfurt.de/SOR_Appendix.pdf
} 


\subsection{European Specifics on Transaction Costs in Order Execution}

While security markets and respective clearing and settlement providers differ in their cost structures for domestic trading, the main driver of explicit costs is cross-system settlement fees for international, pan-European trades:

Trading and post-trading fees are influenced by various parameters for each provider. Those parameters are partly related to the SOR user's trading characteristics. Other parameters concern the characteristics of a specific trade and the market in which it is executed. To reduce complexity we derive the cost contribution of each process activity as depicted in Figure 1. This is consistent with the methodology by [20] who model the variable costs directly related to the execution of trades for the required activity and neglects fix costs. Accordingly, total costs of domestic trading in a specific market for an individual trade are defined as:

$$
\operatorname{Costs}_{\text {Total }}=\operatorname{Costs}_{\text {Trading }}+\operatorname{Costs}_{\text {Clearing }}+\operatorname{Costs}_{\text {Settlement }}
$$

Detailed cost figures and parameters contributing to the calculation of the domestic transaction costs are presented in the Appendix A II.

Cross-system trading refers to situations where an order is executed in a market/country other than the one where the final settlement takes place (i.e. the domestic CSD of the market where the security is primarily listed). In cross-system trading, clearing and settlement, transaction costs depend on the access setup to the respective CSDs. In order to settle a transaction of a particular security, both counterparties must have access to systems enabling them to deliver and receive the security in question. Thus, the distinctive feature of cross-system settlement is how to gain access to a settlement system in another country and/or the interaction of different settlement systems. [6] lists five different access setups for a SOR user to a foreign CSD. We select those two which can be identified as a lower and an upper boundary for the relevant switching costs and design two scenarios assuming one specific level of costs consistent for all SOR users in that scenario:

1. Direct access cost scenario: here the SOR user has direct (non-intermediated) access to foreign CSDs. This means it has direct access to all facilities - trading, clearing and settlement - necessary along the securities trading value chain. Therefore, the direct access cost scenario obviously represents the lower boundary regarding variable switching costs for individual trades.

2. Intermediated cost scenario: here the SOR user depends on intermediaries to access the foreign settlement systems. Among the four potential intermediation services reported by [6], our cost analysis identified ICSDs as a realistic upper cost boundary for which price fees are publicly available.

To evaluate whether a sub-optimal execution still holds after the inclusion of switching costs, the fee determination component of our transaction cost modeller artefact delegates the following switching cost information to the scenario clustering component:

For the direct access cost scenario, the switching costs are defined as the difference of the total costs $\left(\right.$ Costs $\left._{T o t a l}\right)$ for trading, clearing and settlement in the markets, where the trade originally took place to that where it can be executed alternatively. In the intermediated cost scenario this cost difference is extended by additional costs for the 
transfer of the traded stocks. Thereby it is assumed that the respective securities are kept in the CSD of the alternative market causing costs for a delivery or receive instruction at its CSD and a delivery or receive instruction at the ICSD, i.e. one external instruction to the respective market.

\section{Dataset Description and Handling}

Our analysis concentrates on actively traded shares on multiple markets in Euro currency. Thus we select the constituents of the Dow Jones EURO STOXX 50 index (as of October 2007). One constituent (ARCELORMITTAL) is not available in the data. Our analysis focuses on simultaneous trading opportunities among multiple markets to be accessible by SORs. This requires markets featuring fully-electronic open central limit order books. In the investigation period, ten European markets are addressed: Bolsa de Madrid, Borsa Italiana Milan, Chi-X, four Euronext (EN) markets (Amsterdam, Brussels, Paris, and Lisbon), NASDAQ OMX Helsinki, SWX Europe and Deutsche Börse Xetra.

For each security/market combination we retrieve trade and order book data from Reuters. Our sample consists of 20 trading days divided into two distinct sample periods with the first from December 10-21, 2007 and the second from January 7-18, 2008, i.e. after the applicability of MiFID. By excluding the last trading days of 2007 and the first trading days of 2008, we avoid potential end-of-year and beginning-ofyear trading biases. The collected data contains each best bid/offer limit and trade prices with respective volume and a date as well as time stamps with a granularity of one second. To determine the order book side of the alternative market to be compared with the original trade price, we refer to the following classification: trades executed at the best offer are categorised as buy-initiated and those at the best bid limit are said to be sell-initiated. Trades for which a trade direction cannot be determined unambiguously are removed. Moreover, data lacking essential information (e.g. associated volume) are eliminated. As trading hours among the considered ten electronic markets vary slightly, only the periods of simultaneous trading are analysed. Further, to avoid any bias by strong price movements auctions as well as all trading activity within two minutes around them are removed, such that from a total of 9,163,780 trades, 1,152,875 trades (12.58\%) are eliminated.

New limits in a comparison market are considered available when their change arrives within the second of a trade in the original market. Thus they present the most recent order book situation to this trade. With more than one such change within the second of a trade occurrence at one market, the limit resulting in the least savings is taken as a basis for an execution performance comparison in order to retrieve a lower boundary for the improvement potential of the trading process.

Domestic costs for the transaction cost modeller are derived from publicly available data from exchanges, clearing houses and CSDs. Brokerage costs are not included as brokers/trading desks of institutional investors are assumed to constitute the decision point for order routing and consequently their cost structures are taken as the basis of our analysis. The respective transfer costs are derived from the publicly available fee schedules of the two European ICSDs Clearstream Banking Luxembourg and Euroclear Bank (as of late 2007/early 2008). 


\section{Empirical Results}

Our results are based on 8,010,905 trades with a value of $262 \mathrm{bn} €$. They are split into the three cost scenarios: no cost, direct access cost and intermediated cost.

In the no cost scenario, the process optimisation potential allows $6.71 \%$ of the orders to be better executed with their full size $(6.45 \%$ of the orders partially). This enables for total savings of $9.50 \mathrm{~m} €$ within our sample period, i.e. $7.54 \mathrm{bps}$ relative to total sub-optimal execution value and $0.36 \mathrm{bps}$ relative to total traded value. The direct access cost scenario exhibits comparable figures. Even in the intermediated cost scenario, assuming explicit transaction costs like the costs for the transfer of securities, $1.41 \%$ of orders can be better executed with their full size (1.34\% partially). This enables for total savings of $5.90 \mathrm{~m} €$, i.e. $10.17 \mathrm{bps}$ relative to the total sub-optimal execution value and $0.23 \mathrm{bps}$ relative to the total traded value (cf. Table 1).These potential savings outline inefficiencies within the trading process for all three costs scenarios. To validate these descriptive findings, additional statistical tests have been applied (cf. Appendix A III for details concerning the statistical tests). Table 2 outlines their results in two aggregation perspectives: the overall perspective aggregates all sub-optimal executions across all instruments whereas the security perspective aggregates individual securities' test results. Checkmarks highlight where savings significantly exceed costs. For the theoretical no cost scenario significance can be shown for both perspectives. This is obvious as an idealised SOR is designed to detect saving potentials caused by prevailing market inefficiencies and no switching costs are considered. Thus, when defining best execution as trading at the best available prices our results can be interpreted as significant potential to improve the value chain as far as the trading activity (step $1-3$ in Figure 1 ).

Table 1. Descriptive statistics of sub-optimal executions for all instruments

\begin{tabular}{|c|c|c|c|}
\hline All Instruments & $\begin{array}{l}\text { No costs } \\
\text { scenario }\end{array}$ & $\begin{array}{l}\text { Direct access } \\
\text { cost scenario }\end{array}$ & $\begin{array}{c}\text { Intermediated } \\
\text { cost scenario }\end{array}$ \\
\hline Number of trades & \multicolumn{3}{|c|}{$8,010,905$} \\
\hline Value $[\mathrm{m} €]$ & \multicolumn{3}{|c|}{$262,313.9$} \\
\hline Value per trade $[€]$ & \multicolumn{3}{|c|}{32,75} \\
\hline$\%$ full sub-optimal execution & 6.71 & 6.60 & 1.41 \\
\hline$\%$ partial sub-optimal execution & 6.45 & 5.30 & 1.34 \\
\hline Savings [€] & $9,502,869$ & $9,709,864$ & $5,908,346$ \\
\hline Avg. savings per sub-optimal execution [€] & 9.01 & 10.21 & 26.83 \\
\hline Savings/sub-optimal execution value [bps] & 7.54 & 7.80 & 10.17 \\
\hline Savings/trade value[bps] & 0.36 & 0.37 & 0.23 \\
\hline
\end{tabular}

Table 2. Potential of SOR to improve the efficiency of the securities trading value chain

\begin{tabular}{|l|c|c|c|}
\hline & No cost scenario & Direct access cost scenario & Intermediated cost scenario \\
\hline Security perspective & $\checkmark$ & $\checkmark$ & $(\checkmark)$ \\
\hline Overall perspective & $\checkmark$ & $\checkmark$ & $x$ \\
\hline
\end{tabular}


To have a more comprehensive perspective we have to extend the focus to the complete value chain, i.e. including all activities (step $4-6 \mathrm{a} / 6 \mathrm{~b}$ in Figure 1) and considering all applicable costs. Again, for the direct access cost scenario, significant process improvements can be shown for the entire securities trading value chain. This shows that employing SOR leads to an improved process even when considering costs. Unfortunately, the direct access cost scenario is not applicable for all market participants due to their firm size. Small market participants have to employ an additional intermediary (e.g. ICSD) activity (step 6b in Figure 1) providing their access to the alternative markets post-trading infrastructure. Within this intermediated cost scenario results are heterogeneous: whereas on a security perspective for almost one third (16 out of 49) of the considered instruments the potential for process improvement prevails, in the overall perspective no significance can be shown (red X in Table 1). Thus the costs of the additional ICSD activity impede small market participants from taking advantage of the process improvements enabled by SOR.

To highlight an exemplary analysis of this effect for one security, we selected TOTAL as it led the EURO STOXX 50 in terms of market capitalisation (as of December $31^{\text {st }}, 2007$ ) and as it exhibits most trades and belongs to the stocks with the highest overall traded value. Detailed statistics are shown in Table 3, where the "Overall" column summarises across all markets. The upper section of Table 3 provides an overview on markets' activity for TOTAL applying characteristic figures which are identical for all cost scenarios.

Trade activity varies heavily for TOTAL among market places. As common for most stocks, the primary market exhibits more than ten times higher trade numbers then the second largest. In the no cost scenario for TOTAL, $14.58 \%$ or 42,815 out of 293,729 trades at its home market EN Paris could have been executed in their full size at a better price in (at least) one of the other markets. Again, for the direct access cost scenario the figures are comparable $(14.51 \%$ or 42,608$)$ whereas in the intermediated cost scenario only $2.98 \%$ or 8,752 full sub-optimal executions remain.

For the intermediate scenario (cf. Table 3) we $t$-tested the absolute gross savings (savings of the no cost scenario) against their switching costs. Our findings are heterogeneous among stocks: since this scenario incurs explicit costs for domestic transactions and securities transfer as described in section 3.1, the null hypotheses of no systematic absolute savings cannot be statistically rejected for some stocks like TOTAL. Concerning the significance of our results no systematic pattern can be found (cf. Table 3, intermediated cost scenario, mean costs row). Although EN Bruessel (12.26€) and SWX (165.64€) exhibit the highest gross average savings per suboptimal execution (Table 3, no costs scenario section), only EN Brussel's savings remain significant after the inclusion of switching costs (intermediated cost scenario section, mean costs). This is due to EN Bruessel's higher observation number and lower mean switching costs in comprision to SWX Europe and Milan. Regarding the additional intermediary activity (e.g. by an ICSD) this supports the thesis that observable gross average savings per sub-optimal execution (overall more than $0.5 \mathrm{~m} €$ for TOTAL) are nullified by high ICSD costs. Accordingly, small intermediaries cannot profit from more efficient trading processes enabled by SOR. An overview for all instruments is provided in Appendix A IV. 
Table 3. All cost scenarios results for TOTAL

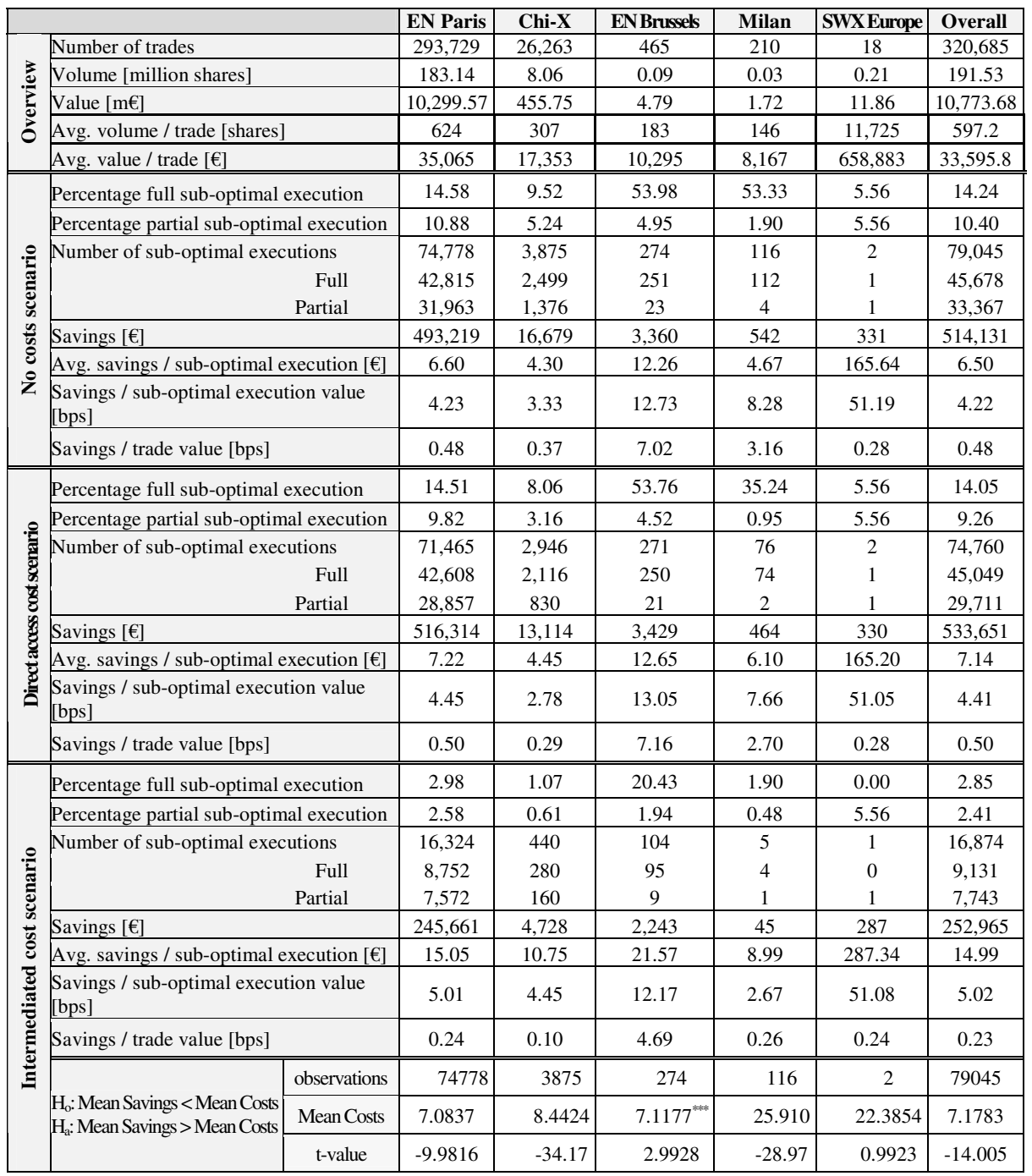

Null hypothesis is rejected at significance level $.10\left(^{*}\right), .05\left(^{* *}\right)$ and $.01\left(^{* * *}\right)$

Altogether our results show that investors could have realised significant savings on their trades across all instruments. Those savings result from execution conditions superior to those in the market of the actual trade even when considering different levels of explicit transaction costs. Although those savings obviously shrink under the highest assumed transaction costs (intermediated cost scenario), still one out of a hundred trades could have been executed at better conditions. 


\section{Conclusion}

Concerning the first research question our results imply that the current routing implementations in Europe exhibit potential for improvement. No definitive answer to the second question can be given: although SOR technology enables for relevant improvements, the ability to profit from this potential is limited to large investors, since smaller investors face relevant explicit costs in post-trading.

The implications are threefold: investors should select large market intermediaries enabling them to profit from their potential to provide best execution. Market access intermediaries should use SOR technology to enable cost savings, comparative advantages and best execution for their customers. European regulators shall enforce initiatives to reduce post-trading costs (e.g. the usage of CSD links) to enable even small market access intermediaries to profit from this optimisation potential.

As a future extension of the analysis, inclusion of more detailed data (like order book depth on millisecond basis) will allow to compute the optimisation potential by enhancing the partial sub-optimal execution concept. Concerning the data evaluation period, we are implementing a concept which enables us to compute the sub-optimal execution results on a continuous basis. Beyond the snap shot approach taken in this paper, this will provide insights on how the securities trading value chain evolves and allows to assess how market participants adopt SOR technology and how efforts to reduce post-trading costs help to improve the overall efficiency of the trading process.

\section{Acknowledgment}

We thankfully acknowledge the support of the E-Finance Lab, Frankfurt for this work.

\section{References}

[1] Schwartz, R.A., Francioni, R.: Equity markets in action: The fundamentals of liquidity, market structure \& trading. Wiley, Hoboken (2004)

[2] Hitt, L.M., Brynjolfsson, E.: Productivity, Business Profitability, and Consumer Surplus: Three Different Measures of Information Technology Value. MIS Quarterly, 121-142 (June 1996)

[3] Harris, L.: Trading and Exchanges - Market Microstructure for Practitioners. Oxford University Press, Oxford (2003)

[4] CESAME Sub-Group on definitions, Commission Services Working Document on Definitions of Post-Trading Activities (October 2005)

[5] Fidessa, Fidessa Fragmentation Index (2009), http: / / fragmentation.fidessa.com/ (last accessed 06/13/2009)

[6] Giovannini Group, Cross-Border Clearing and Settlement Arrangements in the European Union (November 2001), http://ec.europa.eu/internal_market/ financial-markets/docs/clearing/first_giovannini_ report_en.pdf (last accessed: 08/11/2007)

[7] Gomber, P., Pujol, G., Wranik, A.: The Implementation of European Best Execution Obligations - An Analysis for the German Market, FinanceCom, Paris, France (2008) 
[8] Kohli, R., Grover, V.: Business value of IT: An essay on expanding research directions to keep with the times. Journal of the Association for Information Systems 9(1), 23-39 (2008)

[9] Chircu, A.M., Kauffman, R.J.: Limits to Value in Electronic Commerce-Related IT Investments. Journal of Management Information Systems 17(2), 59-80 (2000)

[10] Davern, M.J., Kauffman, R.J.: Discovering potential and realizing value from information technology investments. J. Manage. Inf. Syst. 16(4), 121-143 (2000)

[11] Mooney, J.G., Gurbaxani, V., Kraemer, K.L.: A process oriented framework for assessing the business value of information technology. SIGMIS Database 27(2), 68-81 (1996)

[12] Weyland, J.H., Engiles, M.: Towards simulation-based business process management: towards simulation-based business process management. In: Proc. of the 35th Conf. on Winter Simulation: Driving Innovation, pp. 225-227 (2003)

[13] Yen, V.C.: An Integrated Model for Business Process Measurement. In: CONF-IRM 2008 Proceedings, Paper 9 (2008)

[14] Qureshi, A., Weber, R., Balakrishnan, H., Guttag, J., Maggs, B.: Cutting the electric bill for internet-scale systems. In: Proc. of the ACM SIGCOMM 2009, pp. 123-134 (2009)

[15] Foucault, T., Menkveld, A.J.: Competition for Order Flow and Smart Order Routing Systems. Journal of Finance (63), 119-158 (2008)

[16] Prix, J., Loistl, O., Huetl, M.: Algorithmic Trading Patterns in Xetra Orders. European Journal of Finance 13(8), 717-739 (2007)

[17] Gsell, M., Gomber, P.: Algorithmic trading engines versus human traders - Do they behave different in securities markets? In: Proc. of the 17th European Conference on Information Systems (2009)

[18] Domowitz, I., Yegerman, H.: The Cost of Algorithmic Trading - A First Look at Comparative Performance. In: Bruce, B.R. (ed.) Algorithmic Trading: Precision, Control, Execution, pp. 30-40. Institutional Investor Inc. (2005)

[19] Bakos, Y., Lucas, H.C., Wonseok, O., Viswanathan, S., Simon, G., Weber, B.: Electronic Commerce in the Retail Brokerage Industry: Trading Costs of Internet Versus Full Service Firms, Working Paper Series Stern\#1S99-014 (1999)

[20] Oxera. Methodology for monitoring prices, costs and volumes of trading and posttrading activities (July 2007), http://ec.europa.eu/internal_market/ financialmarkets/docs/clearing/oxera_study_en.pdf (last accessed: $01 / 15 / 2008)$ 